\title{
Attachment characteristics and emotion regulation difficulties among maladaptive and normal daydreamers
}

\author{
Alexandra Sándor ${ }^{1,2}\left(\right.$ CD $\cdot$ Antal Bugán ${ }^{1,2} \cdot$ Attila Nagy $^{3} \cdot$ Lilla Stella Bogdán ${ }^{1} \cdot$ Judit Molnár ${ }^{1,2}$
}

Accepted: 25 February 2021 / Published online: 6 March 2021

(C) The Author(s) 2021

\begin{abstract}
Maladaptive daydreaming is an excessive form of daydreaming which causes significant distress and functional impairment to the affected individuals. Research on maladaptive daydreaming has intensified in recent years, but its pathogenesis has not yet been clearly elucidated. The aim of the study was to examine the attachment characteristics and the difficulties in emotion regulation among maladaptive and normal daydreamers. 717 individuals were recruited online, 106 of whom were screened as maladaptive daydreamers. The results of the Attachment Style Questionnaire revealed a specific attachment style among maladaptive daydreamers, who were characterized by 'Ambivalent-fearful' attachment characteristics, while normal daydreamers showed 'Secure-independent' attachment style. Regarding emotion regulation difficulties, maladaptive daydreamers showed a significantly higher level of deficit on each subscale of the Difficulties in Emotion Regulation Scale compared to normal daydreamers. The findings highlighted the potential role of early attachment experiences in the etiology and pathogenesis of maladaptive daydreaming, as well as the presence of severe emotion regulation deficits among problematic daydreamers. The results revealed by the present study might give contributions to the development of psychotherapeutical treatment of maladaptive daydreaming.
\end{abstract}

Keywords Maladaptive daydreaming $\cdot$ Attachment style $\cdot$ Emotion regulation difficulties $\cdot$ Hungarian sample

\section{Introduction}

\section{Maladaptive Daydreaming}

Daydreaming is a "basic human pastime" constructing around fictional narratives, fantasized relationships and jobs, alternative worlds, personalities and lifestyles (Regis, 2013). Singer (1975), based on his observations and research data accumulated in the field of daydreaming, suggests that daydreaming in general is a normal phenomenon. According to daydreaming research, different styles and patterns of daydreaming exist:

Alexandra Sándor

sandoralexandra@med.unideb.hu

1 Department of Behavioural Sciences, Faculty of Medicine, University of Debrecen, Móricz Zsigmond krt. 22,

Debrecen H-4032, Hungary

2 Doctoral School of Health Sciences, University of Debrecen, Debrecen, Hungary

3 Faculty of Public Health, University of Debrecen, Kassai út 26, Debrecen H-4028, Hungary positive constructive daydreaming (creative, playful, planful thoughts), guilty-dysphoric daydreaming (obsessive fantasies) and poor attentional control (poor concentration on external task or thoughts) (McMillan, Kaufman, \& Singer, 2013; Singer, 1975). When mind-wandering appears as a healthy and constructive mental behavior, it may have a number of benefits, regarding creative problem solving, autobiographical planning, learning and reasoning (Killingsworth \& Gilbert, 2010; Mooneyham \& Schooler, 2013; Regis, 2013). However, in many contexts, mind-wandering means a cost to human functioning, specifically, daydreaming causes deficits in performance: reading comprehension, model building, performance on working memory and on intelligence tests might be impaired (Mooneyham \& Schooler, 2013). In addition to performance, mind-wandering might have an impact on mood. In a study (Killingsworth \& Gilbert, 2010), participants reported to be unhappy when their minds wander, and further analysis revealed that mind-wandering was the cause of their unhappiness, and not a consequence of negative mood. However, Poerio, Totterdell, Emerson, and Miles (2015) revealed that daydreaming about social relationships and interactions was related to an increased level of happiness, love and connection. These emotions were only detected when the 
individual was lacking in positive emotions before daydreaming, and when the daydreamer fantasized about other people with whom he or she has high quality relationships. Results also suggested that daydreams have an important role in emotion regulation, as fantasizing about close others might fit the daydreamer's actual emotional needs. Moreover, social daydreams, which compensate the lack of social feelings, might evoke positive feelings (Poerio et al., 2015).

However, imaginative process or fantasizing is a complex, multifaceted human ability, which in certain cases might become extreme and impairs the individuals' life (West \& Somer, 2020). The pathological form of daydreaming was first described by Somer in Somer, 2002. He based his observations on a small clinical sample, which members were survivors of severe childhood traumatization, and were involved in psychotherapy with the diagnosis of dissociative disorder or personality disorder. In this traumatized clinical group, maladaptive daydreaming might have been developed in childhood as a useful coping strategy against traumatic, aversive experiences - similarly to dissociative disorders-, but later this strategy may have become harmful for everyday functionality of the individual (Somer, 2002). Maladaptive daydreaming was first described as a fantasy activity, which appears in an exaggerated form, and which can be differentiated from normal, adaptive daydreaming (Bigelsen, Lehrfeld, Jopp, \& Somer, 2016; Bigelsen \& Schupak, 2011; Somer, 2002). Later research (Bigelsen et al., 2016; Bigelsen \& Schupak, 2011) confirmed that maladaptive daydreaming differs considerably from normative daydreaming from several aspects. The fantasy content, the intense urge and yearning for daydreaming, the use of kinesthetic activities and listening to music to facilitate and/or maintain the daydreaming episode, reported distress and impaired functionality deriving from the impaired control of the fantasy activity, the excessive time devoted to daydreaming and the interfering effect of the mental activity with real relationships and with achieving goals and plans, as well as intense shame and repeated attempts to hide the behavior from others make the maladaptive form of daydreaming different from its normal variant. Based on these characteristics, Somer and his colleagues (Somer, Lehrfeld, Bigelsen, \& Jopp, 2016, p.87) labelled maladaptive daydreaming as an "unrecognized clinical syndrome". It is difficult to conceptualize this multifaceted phenomenon. Evidence revealed that maladaptive daydreaming is associated with dissociative experiences (dissociative absorption, amnesia and depersonalization). It showed the strongest correlation with absorption, suggesting that maladaptive daydreaming might have dissociative properties and might represent the pathological end of the absorption spectrum (Somer, 2018; Somer, Lehrfeld, et al., 2016). Further results (Somer, Soffer-Dudek, \& Ross, 2017a) indicated that maladaptive daydreamers can be characterized by significant inattention. This might be primarily considered as the consequence of maladaptive daydreaming, due to the intense involvement into the inner reality that impairs the observation of external events. In another study, attention deficit hyperactivity disorder (ADHD), anxiety disorder, depressive disorder and obsessive compulsive or related disorders (OCD) were found as the most frequent comorbid disorders among maladaptive daydreamers $(n=39)$. As high rates of comorbidity between maladaptive daydreaming and several DSM-5 disorders have been found, Somer et al. (2017a) suggest that these findings verify that maladaptive daydreaming is a form of psychopathology. Although the phenomenon shares some similar features with ADHD, OCD and dissociation, "it cannot be better accounted for by any other exiting DSM-5 disorder" (Somer, Soffer-Dudek, \& Ross, 2017a, p. 529).

A new pathway in the conceptualization of maladaptive daydreaming is the behavioral addiction hypothesis. According to this approach, problematic daydreaming might show similarities with behavioral addiction (for example with gambling disorder) (Pietkiewicz, Nęcki, Bańbura, \& Tomalski, 2018; Sándor, Münnich, \& Molnár, 2020; Somer, 2018). Maladaptive daydreamers also have positive emotions (such as excitement and pleasure) deriving from the intense involvement into fantasy; they dedicate more and more time and energy to this activity; they are unable to control daydreaming; they experience negative feelings and frustration when daydreaming is disturbed; and the life impairing effect of this excessive fantasy activity causes intrapsychic conflict. Based on the results of research in the field of maladaptive daydreaming, it can be suggested that further qualitative and quantitative studies would be necessary to identify the phenomenon as a distinct clinical condition or as a symptom or component of other disorders (Pietkiewicz et al., 2018).

\section{Attachment Style and Maladaptive Daydreaming}

Attachment is an irreplaceable affective bond between two organisms, which accompanies human life: provides security, closeness, and protection in emergency situations, as well as comfort and support (Bowlby, 1988; Hámori et al., 2016b). Attachments, particularly those between parent and child, have a continuity over time, exceed everyday interactions and their specificities, and have an important role in children's personality development, happiness and resilience (Bowlby, 1988; Cummings \& Cummings, 2002). This intimate emotional bond is necessary for healthy emotional development and mental health of the offspring (Bowlby, 1988). Confidence in the availability of the caregiver (or the lack of it) develops slowly during infancy, childhood and adolescence. Expectations and forecasts built up on these experiences result in working models or representational models of the world, the attachment figures and the self, and determine the development of personality. These working models tend to 
be unchanged over time. The knowledge that the caregiver is available and sensitively responsive causes the powerful feeling of security. However, the uncertainty about the accessibility of the attachment figure causes fear and insecurity in different situations, which is often experienced as free-floating anxiety (Ainsworth, 1985; Bowlby, 1973; Bowlby, 1982).

Differences in parental behavior influence the infant behavior differently, which leads to the development of patterns of attachment (Ainsworth, 1985). Those children who experience security, responsiveness and support are likely to follow healthy pathways of personality development. However, if the parent is not available and responsive enough, misses to fulfill the child's core needs, or in cases of abuse, severe neglect or parental mental illness, an insecure, anxious, or even a disorganized attachment behavior might develop. These children are more vulnerable to follow personality developmental pathways that are more likely to be incompatible with mental health (Bowlby, 1988).

The pattern of attachment is self-perpetuating, tends to persist and becomes predictive regarding the later attachment behavior with parents and with the loved ones (Bowlby, 1988). The capacity to create close, intimate bonds in adulthood reflects an effective functioning and mental health (Bowlby, 1988). However, if there is a missing secure base, and the extent of acceptance, love and positive experiences provided by the early attachment figure is insufficient, this might increase the probability of inadequate emotional and behavioural patterns accompanying the whole life (Palitsky, Mota, Afifi, Downs, \& Sareen, 2013). As an adult, individuals with unsafe attachment patterns see the world as unpredictable, and other people as unlikely to be available, supportive or comforting (Ainsworth, 1985; Bowlby, 1973; 1982).

Examination and description of the characteristics of child and adult attachment styles have been in the focus of research for a long time. Results suggest that insecure attachment styles link to a higher level of psychopathology, while secure attachment styles are related to a lower probability of psychopathology. Furthermore, according to research results the more insecure the adult attachment was the more severe the mental pathologies were, particularly in cases of anxiety and mood disorders, impulse control disorders, substance use disorders, and suicidal ideation and attempt (Palitsky et al., 2013).

However, a research gap exists in the literature of maladaptive daydreaming, as -to the best of our knowledgeexcessive daydreamers' attachment style has not been analysed yet. Previous studies revealed that one function of maladaptive daydreaming is to compensate for the deficits of basic needs (Somer, 2002; Somer, Somer, \& Jopp, $2016 \mathrm{a} ; \mathrm{b})$. The inner world of problematic daydreamers is often built around romantic relationships, an imaginary family or friends, relationships with others, like celebrities or a fantasized ideal self, while normal daydreamers fantasize about their real life or have specific wishful daydreams (e.g. winning the lottery) (Bigelsen et al., 2016). A subsequent study (Somer, Somer, \& Jopp, 2016b) confirmed that the most significant themes of maladaptive daydreaming were family and love, competency, social recognition, and social support. The imagined family and ideal relationships might become so rewarding for maladaptive daydreamers that they would rather choose spending time in their fantasy than choosing real life scenarios or other forms of recreation. Furthermore, maladaptive daydreamers' intense need for success, power and recognition, and the consequential sense of inadequacy might be caused by the exposure to critical parental behaviour during childhood and later on (Somer, Somer, \& Jopp, 2016b). Studies also revealed that retreating into the fantasy world, i.e. problematic daydreaming initiated early, typically during childhood (Bigelsen \& Schupak, 2011; Somer, 2002). According to Somer, Somer, and Jopp (2016a), maladaptive daydreamers possess an innate capacity for vivid fantasizing, which by itself cannot lead to pathological daydreaming, but other conditions (for example childhood loneliness, rejection or trauma) would be necessary to account for maladaptive daydreaming.

As early expectations and beliefs about the availability of the caregiver, basic childhood experiences regarding security and confidence, and the consequentially built working models, tend to persist over time (Bowlby, 1973), it can be presumed that maladaptive daydreaming might be developed as a protective shield against aversive impacts, or a form of distraction from negative experiences (such as rejection, disappointment, loneliness). Daydreaming activity might function as a source of security, intimacy, positive emotions and attenuator of negative feelings created by compensatory fantasies (Somer, 2002; Somer, Somer, \& Halpern, 2019; 2016a). These findings suggest that (early and consequential later) attachment deficiencies and problems might play an important role in the pathogenesis and maintenance of the disorder; thus, the examination of attachment characteristics formed one aim of the present study.

\section{Emotion Regulation and Maladaptive Daydreaming}

"Emotion regulation consists of internal and external processes involved in initiating, maintaining, and modulating the occurrence, intensity, and expression of emotions" (Morris, Silk, Steinberg, Myers, \& Robinson, 2007, p. 363). Emotion regulation processes determine the emotional experience significantly, as these processes influence the quality, intensity, dynamics, and timing of emotions (Thompson, 1994). The development of emotion regulation abilities is influenced by intrinsic mechanisms (neurologic, genetic and temperamental influences), as well as by several external, social factors: social interactions with parents, peers and teachers; impacts of culture and media. Among all these factors, researchers 
attribute a privileged role in the development of children's emotion regulation abilities to parental influences, - in particular, parental emotion regulation and emotion expression, parenting style, and parents' responsiveness to children's emotional reactions (Bariola, Gullone, \& Hughes, 2011).

Attachment relationship in childhood influences significantly children's expectations of the parental behavior (i.e. working models), and consequently influences children's emotion regulation abilities (Cassidy, 1994). Secure attachment and its associated characteristics (the more accurate assessment and understanding of the child's emotions, compassionate communication about the emotions, and more effective support of the child) have an impact on the child's emotion regulation processes and their efficiency (Waters et al., 2010). Indeed, one of the essential functions of the attachment relationships is supporting children to regulate their emotional arousal, particularly in case of threatening or distressful emotions, facilitating in this way the development of emotional self-awareness and effective emotion regulation abilities (Thompson, 2008). A longitudinal study (Kochanska, 2001) assessed emotional development through emotional responding, specifically the features of the functioning of three affect systems (anger, fear, joy) in response to simple affective stimuli, in a sample of children $(\mathrm{n}=112)$ with different attachment histories. From infancy to 33 months in case of children with avoidant and disorganized/unclassifiable attachment styles, negative emotions significantly increased, while in case of resistant children positive emotions decreased. At 33 months, secure children showed less fear and anger in episodes eliciting fear or anger, and responded with less distress to episodes evoking joy.

In a 10-year longitudinal study (Pascuzzo, Moss, \& Cyr, 2015), the relationship between adolescent attachment, adult romantic attachment, emotion regulation strategies and symptoms of psychopathology in adulthood were assessed. The results revealed that adolescents' greater attachment insecurity to parents predicted greater self-reported psychopathology in young adulthood, which association was mediated partially by the use of emotion-focused regulation strategies (e.g. selfblame, ruminative thoughts).

Another study compared emotion regulation in a group of children whose mothers have borderline personality disorder to a normative group, using narrative story-stem measure. Examining the whole sample, children's maladaptive emotion regulation was related to maternal identity disturbance, negative relationships and self-harming behavior, and marginally associated to maternal affective instability (Macfie \& Swan, 2009). Cooper, Shaver, and Collins (1998) found that in a sample of adolescents $(n=1989)$, securely attached individuals reported better adjustment, more positive self-concepts, higher level of intellectual and social competence, lower levels of depression and hostility than avoidant and anxiousambivalent respondents. Anxious adolescents seemed to be the worst-adjusted group with the poorest self-concepts and showing the highest levels of symptomatology and risk behaviors, while avoidant individuals - although reported high levels of symptomatology and poor self-concepts- showed levels of risk behaviors similar to those reported by securely attached adolescents.

Adaptive emotion regulation is necessary to work effectively, have successful relationships and possess adequate psychic resources (Gross \& Muñoz, 1995), while emotion regulation dysfunctions might lead to several undesirable consequences regarding mental health (Mortazavizadeh \& Forstmeier, 2018). According to research findings, deficits in the ability to cope with difficult emotions are related to depression, borderline personality disorder, eating disorders, somatoform disorders, substance-use disorders and other psychopathological symptoms (Berking \& Wupperman, 2012).

Maladaptive daydreaming is strongly associated to emotions and emotion regulation, as it involves the attenuation of negative emotions, as well as the creation and experience of positive emotions. Excessive and intense daydreaming functions as an attempt to escape from difficulties and painful experiences (Somer, Somer, \& Jopp, 2016a). Fantasy world can ease the experience of distress, the level of anxiety, feelings of loneliness and isolation, as well as social life deficiencies (Somer, Somer, \& Jopp, 2016a). Another benefit of the imagination is that it enables the individual to experience positive emotions that are missing in life. Daydreaming, apart from facilitating the process of relief and relaxation, helps the daydreamer to experience joy, happiness, and even euphoric feelings. Fantasizing and daydreaming activity might aid the individual to experience a higher level of empathy towards others and to understand the emotions more easily, as these abilities might progress by anticipating and imagining social situations (Bigelsen \& Schupak, 2011). A recent study (Somer et al., 2019) empirically confirmed that maladaptive daydreaming enables the individual to regulate emotions to some extent and create protection against external and internal reality.

It must be emphasized that though maladaptive daydreaming is an attempt to regulate emotions, it is not an effective or adaptive form of emotion regulation. According to a new study (West \& Somer, 2020), there is a subgroup of maladaptive daydreamers: these individuals daydream in a vivid, intense and detailed way, however, they do not suffer from the negative consequences of maladaptive daydreaming. These daydreamers are called as "immersive daydreamers (IMers)". Presumably, immersive daydreamers possess better emotion regulation strategies compared to maladaptive daydreamers characterized by severe distress and functional impairment. However, results of the study revealed that both the maladaptive factor (MDSmaladaptation) and the immersive factor (MDS-immersion) of maladaptive daydreaming correlated positively with the Difficulties in Emotion Regulation Scale (DERS) score. 
Maladaptive daydreamers characterized by maladaptive symptoms (MDS-maladaptation), indeed, suffered from more severe emotion regulation difficulties based on their DERS scores, but immersive daydreamers (MDS-immersion) also showed poor emotion regulation abilities, even if their score was slightly lower than the score of daydreamers characterized by maladaptive components. Researchers suggested that neither form of maladaptive daydreaming functions as an effective emotion regulation strategy.

Greene, West, and Somer (2020) also investigated the associations between the symptoms of problematic daydreaming and emotion regulation difficulties. Results of the study confirmed that weaker emotion regulation abilities were related to a higher degree of maladaptive daydreaming symptoms. An interesting result of their research was that the lack of emotional clarity and enjoyment of daydreaming correlated negatively, thus, the more enjoyable the daydreaming is, the more processable the emotions become, which might lead to an increased emotional clarity (Greene et al., 2020). Regarding the functions of maladaptive daydreaming and the findings of previous research, it was hypothesised that emotion regulation deficits may play an important role in the development and maintenance of maladaptive daydreaming.

\section{The Present Study}

The present study aimed to assess the attachment characteristics and emotion regulation difficulties among maladaptive daydreamers and to compare them to the corresponding characteristics of normal daydreamers. As attachment characteristics of maladaptive daydreamers have not been investigated yet, the first aim of the study was to identify specific attachment patterns in the two study groups. Attachment characteristics were examined through five dimensions: the importance of relationships for the self; confidence in relationships; ambivalence experienced in close relationships; dependency-independency; self-advocacy. Another aim of the study was to explore potential emotion regulation difficulties of maladaptive daydreamers and compare them to normal daydreamers. The third aim of the study was to reveal the relationship between the dimensions of attachment and emotion regulation in the group of maladaptive daydreamers.

Overall, the main purpose of the research was to identify some potentially important segments of the etiology and pathogenesis of maladaptive daydreaming, and consequently to broaden the knowledge about the phenomenon, to inspire further research in the field and in the long term to promote the development of effective therapeutic approaches for the treatment of maladaptive daydreaming.

After the brief summary of the literature related to maladaptive daydreaming, attachment and emotion regulation, and presenting the connections between these constructs, in the
Method section sampling procedure, the applied measures and the statistical tests used to analyse data are described. Following the presentation of the demographic characteristics of the sample, results about the comparison of the attachment characteristics and emotion regulation deficits between the study groups, and the detailed examination of the relationship between the dimensions of attachment and emotion regulation deficits in maladaptive daydreamers' group are shown in the Results section. After discussing the results, as well as the strengths and limitations of the study, major conclusions are drawn in the Conclusion section of the article.

\section{Method}

\section{Sampling Procedure}

The recruitment process of study participants was carried out in two stages. In the first stage, individuals were recruited from Facebook online communities using the snowball sampling method; these participants could access the questionnaire package via an Internet link only after reading the research enquiry and giving informed consent to study participation. During the first stage, 243 individuals filled in the questionnaire package, 48 of whom were screened as maladaptive daydreamers based on the Hungarian cut-off score (established at 60 percentiles) of the Maladaptive Daydreaming Scale (MDS-16, Somer, Soffer-Dudek, Ross, \& Halpern, 2017b), the MDS-16-HU (MDS-16-HU, Sándor et al., 2020).

In the second stage, Hungarian students of the University of Debrecen were informed about the possibility of participating in the study via email through the Neptun Unified Education System. They could access the questionnaire package through the EvaSys web-based software. Using this method, 21.595 individuals received the participation invitation email, $2.2 \%$ of whom, i.e. 474 individuals, filled in the questionnaires. Based on the cut-off score of the MDS-16-HU, 58 participants were identified as maladaptive daydreamers.

Online data collection was justified by the fact that it is challenging to reach the research target group in any other way. Previous studies clearly indicated that individuals affected by maladaptive daydreaming feel intense shame and make efforts to hide their excessive fantasy activity from family members, friends, and even within a trusting therapeutic relationship they never talk about the phenomenon (Bigelsen \& Schupak, 2011; Pietkiewicz et al., 2018; Schimmenti, Sideli, La Marca, Gori, \& Terrone, 2019; Somer, Somer, \& Jopp, 2016a). The results of previous international studies (Bigelsen et al., 2016; Bigelsen \& Schupak, 2011; SofferDudek \& Somer, 2018; Somer, Lehrfeld, et al., 2016; West $\&$ Somer, 2020) also confirmed that online data collection is 
appropriate, as it provides complete anonymity, voluntary participation and facilitates honest answering.

Approval for the study was obtained from the Regional Institutional Research Ethics Committee at the Clinical Center of the University of Debrecen and by the Medical Research Council. The study was conducted in line with the Helsinki Declaration. Study participants were informed in line with research ethics guidelines (e.g. Szentmiklósi, 2011), and they gave their written informed consent to participation in the study. Participation in the study was anonymous, voluntary, and involved one inclusion criterion, that the participant had reached the age of 18 .

\section{Measures}

Demographic Data Age, gender, marital status, level of education and employment status were asked by the participants. Study participants also reported their self-identified maladaptive daydreamer status: based on the screening question for maladaptive daydreaming (Somer, Soffer-Dudek, Ross, \& Halpern, 2017b, p.180), study participants could decide if the description of problematic daydreaming is true or false for them.

MDS-16-HU The phenomenon of maladaptive daydreaming was differentiated from normal daydreaming applying the Maladaptive Daydreaming Scale (MDS-16, Somer, SofferDudek, Ross, \& Halpern, 2017b). The self-report questionnaire consists of 16 items which can be rated on an 11-point Likert scale ranging from $0 \%$ to $100 \%$. Adaptation of the scale for Hungarian use was performed by Sándor et al. (2020), establishing the cut-off score at 60 percentiles ( 35 points). It should be mentioned that the MDS-16-HU is a reasonable choice for the screening of potential maladaptive daydreamers, but it is not a diagnostic tool. Cronbach's alpha was 0.9231 in the present study.

ASQ-H Adult attachment characteristics were measured by the Hungarian version of the Attachment Style Questionnaire (ASQ-H, Feeney, Noller, \& Hanrahan, 1994; adapted for Hungarian use by Hámori et al., 2016a). One specificity of the questionnaire is that the items focus on the significant relationships in general, not only on the romantic relationships, thus this questionnaire can be filled by those individuals who have never had a romantic relationship. The questionnaire consists of 40 items which can be rated by the respondents on a 6 -point Likert scale ( $1=$ Totally disagree, $6=$ Totally agree). The Hungarian version of the scale measures five factors, which loaded on two main factors: Attachment (Importance of Relationships for self; Ambivalence, Distance from relationships, Devaluation of self; Confidence in Relations) and Self-advocacy, Independency [Self-advocacy (against relationships); Dependency, Independency]. Items of the Ambivalence, Distance from relationships, Devaluation of self, play an important role in both main factors, however, this scale belongs to the Attachment main scale more strongly (Hámori, Dankháziné, Horváth-Szabó, et al., 2016a). Cronbach's alpha of the questionnaire was 0.9070 in the present study.

As the scales of the ASQ-H differ from the original version of the ASQ (Feeney et al., 1994), it seemed to be necessary to give a more detailed description of these scales (Hámori, Dankháziné, Horváth-Szabó, et al., 2016a):

(1) Importance of Relationships for Self (IRS): measures the emotional importance of the relationships regarding the self (self- evaluation, self-determination, self-confidence). For those individuals who score higher on this scale the need for close relationships, the presence and opinion of others, and the approval by other people are significant. Furthermore, they are often worried about their relationships and are particularly preoccupied if others do not get as close to them as they wish; often feel that others leave them out of something or experience loneliness, disappointment in others, or the feeling that they are not valuable enough in their relationships.

(2) Ambivalence, Distance from relationships, Devaluation of self $(A D D)$ : measures the degree of intimacy avoidance, ambivalence and devaluation of self. Those individuals who score higher on the scale, experience mixed, ambivalent feelings or feel uncomfortable when they are too close to other people, and they prefer to be alone. Furthermore, they are worried when other people get closer to them; do not truly understand why other people would like to make contact with them; invest less energy in relationships, and their relationships seem to be superficial. These individuals are less prone to burden other people with their problems, or if they share their problems with others, they feel ashamed or ridiculous.

(3) Confidence in Relations (CR): measures the security experienced in relationships. Those people who score higher on this scale are confident in their relationships, easily trust other people and it is easy for them to get close to others. They see themselves as valuable and believe that other people would love and respect them. They feel secure in their relationships and believe that they can count on other people when needed.

(4) Self-advocacy (against relationships) (SA): measures self-advocacy, effectiveness and sense of duty (not necessarily at the expense of relationships). Higher scores on the SA scale indicate that the individual believes that requesting support from others is a sign of failure, the preciousness of someone is determined by the accomplishments, and fulfilment of obligations and tasks, as well as effectiveness prevail over relationships. 
(5) Dependency, Independency (DI): measures the degree of dependence and independence from others. Those who score higher on this scale tend to count on themselves rather than on other people, as well as dependence on others causes difficult and uncomfortable feelings to them.

When adapting the ASQ to Hungarian in a representative sample regarding the age and marital status $(n=1172)$, Hámori and her colleagues identified four attachment types: secure with dependency; secure with independency; dismissive and ambivalent-fearful (Hámori, Dankháziné, Sz, et al., 2016b, see Table 3 on p. 67.):

(1) Security with dependency: individuals characterized by this attachment type have a high $\mathrm{CR}(\mathrm{M}=4.65, \mathrm{SD}=$ $0.59)$, a moderate IRS $(\mathrm{M}=3.35, \mathrm{SD}=0.71)$, a low ADD $(\mathrm{M}=2.03, \mathrm{SD}=0.49)$, a low $\mathrm{SA}(\mathrm{M}=1.97$, $\mathrm{SD}=0.65)$, and a low/moderate $\mathrm{DI}(\mathrm{M}=2.8, \mathrm{SD}=$ $0.59)$ mean scores. These individuals are confident in their relationships; have a positive self-esteem and relationships are important for their self-esteem. They can accept the closeness with other people without ambivalent feelings, and their need for self-advocacy and for relationships are in balance. Dependency on other people is experienced as pleasurable.

(2) Security with independency: individuals characterized by this attachment type have a high $\mathrm{CR}(\mathrm{M}=4.51, \mathrm{SD}=$ $0.49)$, a moderate IRS $(M=3.27, S D=0.54)$, a low ADD $(\mathrm{M}=2.01, \mathrm{SD}=0.45)$, a low $\mathrm{SA}(\mathrm{M}=2.06$, $\mathrm{SD}=0.62)$, and a high $\mathrm{DI}(\mathrm{M}=4.55, \mathrm{SD}=0.67)$ mean scores. Individuals characterized by this attachment style trust in their relationships, have a positive self-esteem and believe that their relationships are important for their self-esteem. They do not experience ambivalence about their relationships, and they can accept the closeness with other people. They are characterized by a high level of independency, but their self-advocacy does not go at the expense of relationships.

(3) Dismissive (avoidant) type: individuals characterized by this attachment type have a moderate CR $(\mathrm{M}=3.86$, $\mathrm{SD}=0.63)$, a moderate/low IRS $(\mathrm{M}=2.82, \mathrm{SD}=0.49)$, a moderate/low $\mathrm{ADD}(\mathrm{M}=2.7, \mathrm{SD}=0.66)$, a moderate $\mathrm{SA}(\mathrm{M}=3.2, \mathrm{SD}=0.87)$, and a moderate $\mathrm{DI}(\mathrm{M}=3.16$, $\mathrm{SD}=0.75)$ mean scores. They moderately trust in their relationships and consider their relationships less important regarding their self-esteem which is neither negative nor positive. They do not experience ambivalent feelings in their relationships and their need for dependency and independency is moderate. They believe that selfadvocacy is primary to relationships.

(4) Ambivalent- fearful type: individuals characterized by this attachment type have a moderate CR $(\mathrm{M}=3.58$,
$\mathrm{SD}=0.69)$, a high IRS $(\mathrm{M}=4.15, \mathrm{SD}=0.52)$, a moderate $\mathrm{ADD}(\mathrm{M}=3.28, \mathrm{SD}=0.64)$, a low/moderate $\mathrm{SA}$ $(\mathrm{M}=2.82, \mathrm{SD}=0.92)$, and a high $\mathrm{DI}(\mathrm{M}=4.35, \mathrm{SD}=$ $0.94)$ mean scores. They moderately trust in their relationships, and they experience ambivalence in them. They prioritise less or moderately their self-esteem over relationships. Although they believe that relationships are significant for self-determination, they prefer to be independent in them (Hámori, Dankháziné, Sz, et al., 2016b, see Table 3 on p.67).

DERS Emotion regulation deficits were assessed by the Difficulties in Emotion Regulation Scale (DERS, Gratz \& Roemer, 2004; adapted for Hungarian use by Gy, 2008). The 36-item questionnaire, rated on a 5-point Likert scale [1 = almost never $(0-10 \%) ; 5=$ almost always $(91-100 \%)$, measures the following factors (Gratz \& Roemer, 2004; Gy, 2008):

(1) Non-Acceptance of Emotional Reponses: measures the experience of negative secondary emotional responses, which means that the individual reacts with intense negative emotions when experiences a negative emotion or shows non-accepting reactions to distress.

(2) Difficulties Engaging in Goal-Directed Behavior: measures the difficulties in concentrating or accomplishing tasks when the individual experiences negative emotions.

(3) Impulse Control Difficulties: measures difficulties in remaining in control of the behavior when the individual experiences negative emotions.

(4) Lack of Emotional Awareness: measures whether the individual is aware of the emotional signals and acknowledges the importance of these signals.

(5) Limited Access to Emotion Regulation Strategies: measures that when the individual experiences negative emotions, believes that this mental state (i.e. being upset) will last a long time and little he or she can do to regulate these emotions.

(6) Lack of Emotional Clarity: measures whether the individual can identify the emotions that are currently experienced.

Cronbach's alpha of the DERS was 0.9480 in the present study.

\section{Statistical Analysis}

The normality of the data was checked with the Shapiro-Wilk test. The Mann-Whitney U test was performed due to the non-normal distribution, to compare the attachment characteristics of maladaptive and normal 
daydreamers. The Mann-Whitney $\mathrm{U}$ test was also applied to examine the differences between the two study groups regarding the difficulties in emotion regulation. The strength of the relationship between the dimensions of attachment and emotion regulation difficulties in the group of maladaptive daydreamers was measured by Spearman's correlation.

Intercooled Stata version 13.0 was used for the statistical analyses. A flowchart of the research methodology was created based on the article An et al., 2019 (p.80). Figure 1 summarizes the research methodology used in the present study.

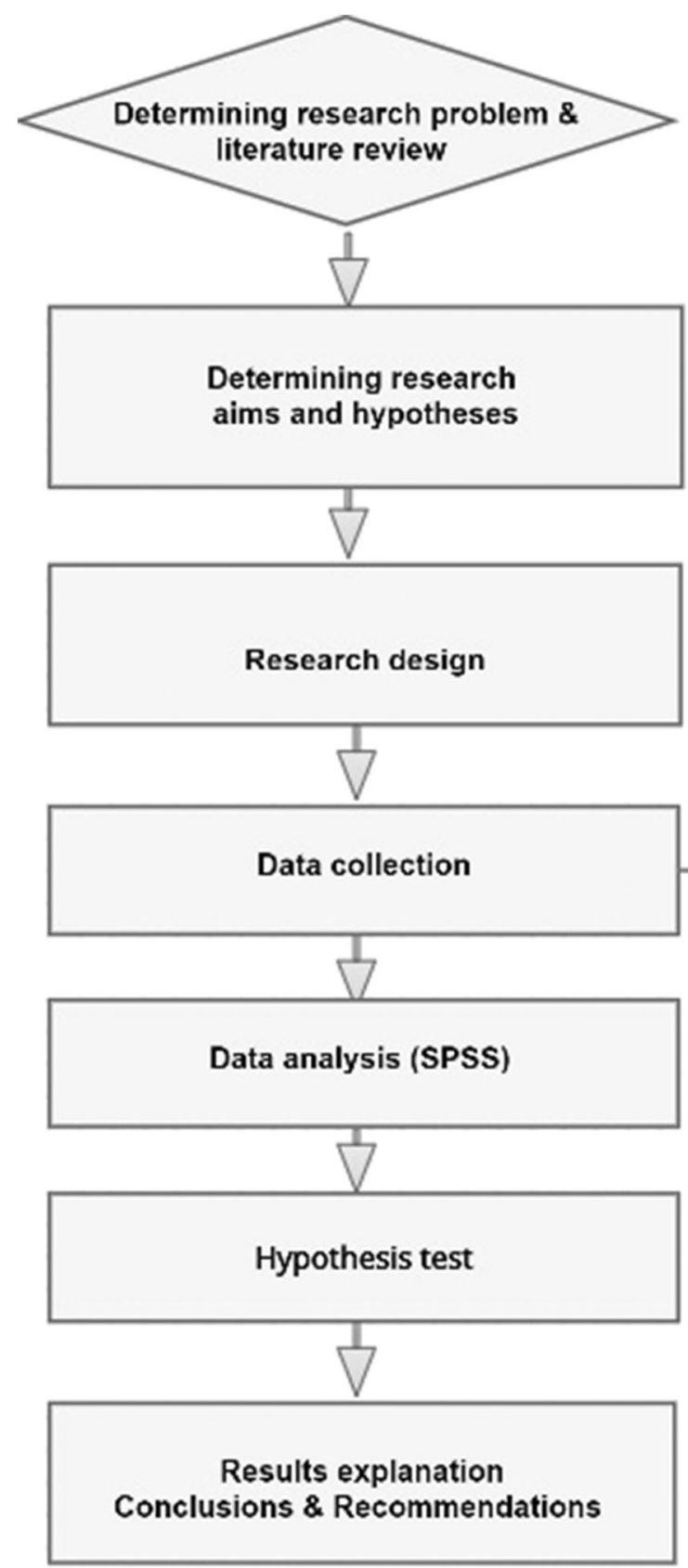

Fig. 1 Research methodology flowchart

\section{Results}

\section{Demographic Characteristics of the Study Samples}

During the initial online recruitment process, 243 participants from various Facebook communities and groups filled in the questionnaire package. Based on the cut-off score of the MDS-16-HU (Sándor et al., 2020), 48 individuals (19.75\%) were screened as maladaptive daydreamers; participants' ages ranged from 18 to 78 years $(\mathrm{M}=36.43 ; \mathrm{SD}=12.45)$, and $76.95 \%$ were women $(n=187)$. During the second stage of the recruitment procedure, $2.19 \%$ of the Hungarian students of

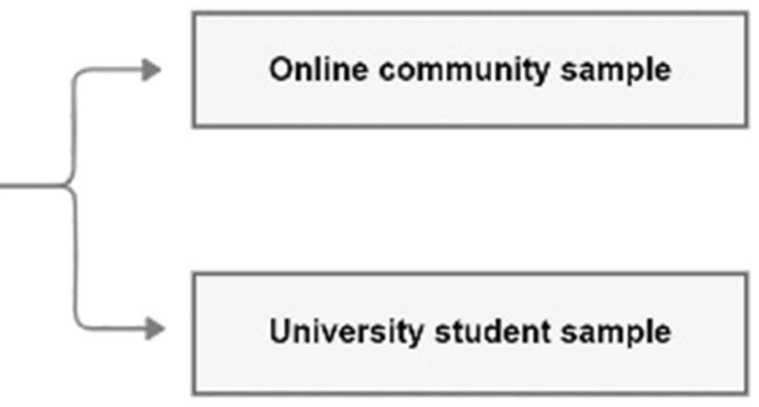


the University of Debrecen (from a total of 21.595 students), 474 persons responded to the questionnaires. Among these participants 58 were identified as maladaptive daydreamers (12.24\%); participants' age ranged from 18 to 58 years $(\mathrm{M}=26.06 ; \mathrm{SD}=8.55)$ and the gender distribution seemed to be similar to the first sample, as $73.84 \%$ of the participants $(n=350)$ were women.

The aim of the present study was to examine the differences between maladaptive and normal daydreamers regarding the attachment characteristics and emotion regulation, therefore the online community sample and the university student sample were combined. The overall sample consisted of 717 persons, 106 of whom were screened as maladaptive daydreamers (14.78\%). A chi-square test showed no significant differences regarding the gender distribution of the two groups $(\chi 2(1)=0.1136, p=0.736) ; 75.12 \%$ of normal daydreamers and $73.58 \%$ of maladaptive daydreamers were women. An Independent Sample T-test revealed significant differences regarding the age $(\mathrm{t}(715)=3.2576, p=0.0012)$, as maladaptive daydreamers $(M=26.33, S D=8.71)$ seemed to be significantly younger than normal fantasizers $(M=30.13$, $\mathrm{SD}=11.46$ ). Significant differences were found between the study groups regarding marital status (Fisher's exact test, $p<0.001$ ), education (Fisher's exact test, $\mathrm{p}<0.001$ ) and employment status $(\chi 2(4)=25.0356, p<0.001)$. As for the marital status, more than a half of the maladaptive daydreamers' group (55.66\%) reported to have single relationship status, $38.68 \%$ were in relationship or married, $3.77 \%$ were divorced, $1.89 \%$ were widowed compared to the normal daydreamers' group, where $34.21 \%$ were single, $60.07 \%$ were in relationship or married, $5.4 \%$ were divorced and $0.33 \%$ were widowed. As for the education, among maladaptive daydreamers secondary education was dominant $(63.21 \%), 2.83 \%$ had primary education, $33.96 \%$ had tertiary education, whereas normal daydreamers reported to have secondary $(51.97 \%)$ and tertiary education $(48.03 \%)$ at a similar rate. Regarding the employment status, $57.55 \%$ of maladaptive daydreamers were student, $20.75 \%$ were employed at the time of the research, $15.09 \%$ were student and employed at the same time and $6.6 \%$ reported to have other type of employment status. In the group of normal daydreamers, $40.43 \%$ were student, $24.55 \%$ were employed, $32.08 \%$ were student and employed, 1.15 were retired and $1.8 \%$ reported to have other type of employment status. Regarding the self-identified maladaptive daydreamer status, false self-identification was relatively higher among those individuals who reported to be normal daydreamers, but who based on the cut-off score of MDS-16-HU, were screened as maladaptive daydreamers $(28.30 \%)$; while $9.33 \%$ of the participants who reported to be maladaptive daydreamers, were identified as normal daydreamers.

\section{Examination of Attachment Characteristics among Maladaptive and Normal Daydreamers}

The first aim of the study was to analyse the differences of adult attachment characteristics among maladaptive and normal daydreamers. Study groups were compared based on the medians scored on the five scales of the ASQ-H examined by the Mann-Whitney $U$ test.

Regarding the three scales of the Attachment main factor, i.e. the IRS (Importance of Relationship for Self), the CR (Confidence in Relations) and the ADD (Ambivalence, Distance from relationships and Devaluation of self), significant differences were found between maladaptive and normal daydreamers. Maladaptive daydreamers scored significantly higher on the IRS and ADD scales, while on the CR scale excessive daydreamers showed a significantly lower score compared to normal daydreamers.

Regarding the two scales of the Self-advocacy, independency main factor, i.e. the SA (Self-advocacy [against relationships]) and the DI (Dependency, Independency), maladaptive daydreamers scored significantly higher than normal fantasizers. Table 1 shows the comparison of the two groups' medians and interquartile range (Q25, Q75) on each scale.

To examine the potential attachment type of maladaptive and normal daydreamers, the mean scores (and standard deviations) of the two groups scored on each scale of the ASQ-H were calculated.

Maladaptive daydreamers showed a moderate CR, a high IRS, a moderate ADD, a low/moderate SA and a high DI mean score, while normal daydreamers showed a high $\mathrm{CR}$, a moderate IRS, a low/moderate ADD, a low SA, and a high DI score. Table 2 shows the mean scores and standard deviations of each scale in the two study groups.

\section{Examination of Emotion Regulation Difficulties among Maladaptive and Normal Daydreamers}

The research hypothesis was that maladaptive daydreamers are characterized by more and/or more severe emotion regulation deficits compared to normal daydreamers. Study groups were compared based on the medians scored on the subscales of the DERS examined by the Mann-Whitney $U$ test.

The results showed that maladaptive daydreamers scored significantly higher on each subscale of the DERS compared to normal daydreamers. These differences between the study groups manifested regarding the total DERS score as well. Table 3 shows the comparison of the two groups' medians and interquartile range $(\mathrm{Q} 25, \mathrm{Q} 75)$ on each subscale. 
Table 1 Median, interquartile range and $p$ value in the study groups for the dimensions of attachment

\begin{tabular}{|c|c|c|c|c|}
\hline Main factor & Scale & $\begin{array}{l}\text { Maladaptive daydreamers } \\
\text { Mdn } \\
\text { (Q25-Q75) }\end{array}$ & $\begin{array}{l}\text { Normal daydreamers } \\
\text { Mdn } \\
\text { (Q25-Q75) }\end{array}$ & $\mathrm{p}$ value \\
\hline Attachment & Importance of Relationship for Self (IRS) & $\begin{array}{l}4.04 \\
(3.46-4.69)\end{array}$ & $\begin{array}{l}3.15 \\
(2.69-3.85)\end{array}$ & $<0.001$ \\
\hline Attachment & Confidence in Relations (CR) & $\begin{array}{l}3.3 \\
(2.5-3.8)\end{array}$ & $\begin{array}{l}4.1 \\
(3.4-4.6)\end{array}$ & $<0.001$ \\
\hline $\begin{array}{l}\text { Attachment; Self-advocacy, } \\
\text { independency }\end{array}$ & $\begin{array}{l}\text { Ambivalence, Distance from relationships, } \\
\text { Devaluation of self (ADD) }\end{array}$ & $\begin{array}{l}3.56 \\
(2.78-4.33)\end{array}$ & $\begin{array}{l}2.56 \\
(2.11-3.22)\end{array}$ & $<0.001$ \\
\hline Self-advocacy, independency & Self-advocacy (against relationships) (SA) & $\begin{array}{l}2.8 \\
(2.2-3.6)\end{array}$ & $\begin{array}{l}2.6 \\
(2-3.2)\end{array}$ & $=0.0012$ \\
\hline Self-advocacy, independency & Dependency, independency (DI) & $\begin{array}{l}5 \\
(4-5.67)\end{array}$ & $\begin{array}{l}4.67 \\
(3.67-5.33)\end{array}$ & $=0.0046$ \\
\hline
\end{tabular}

\section{Examination of the Relationship between the Dimensions of Attachment and Emotion Regulation Difficulties among Maladaptive Daydreamers}

The third aim of the study was to analyse the correlations between the dimensions of the ASQ-H and the DERS in the group of maladaptive daydreamers. As according to the Shapiro-Wilk W test data does not follow normal distribution, the strength of the relationship between the variables was measured by Spearman's correlation. Table 4 shows the results of the correlations between the five dimensions of attachment and the six dimensions of emotion regulation difficulties in the group of maladaptive daydreamers. Based on Prion and Haerling (2014), we interpret Spearman rho 0 to \pm 0.20 negligible, \pm 0.21 to \pm 0.40 weak, \pm 0.41 to \pm 0.60 moderate, \pm 0.61 to 0.80 strong and \pm 0.81 to 1.00 very strong.

In maladaptive daydreamers' group, IRS scale showed a moderate significant positive correlation with Limited Access to Emotion Regulation Strategies and a weak significant positive correlation with Non-Acceptance of Emotional Responses, Difficulties Engaging in Goal- Directed Behavior, Impulse Control Difficulties and Lack of Emotional Clarity. CR scale showed a moderate significant negative correlation with Limited Access to Emotion Regulation Strategies, a weak significant negative correlation with Non-Acceptance of Emotional Responses, Lack of
Emotional Awareness and Lack of Emotional Clarity. A moderate significant positive correlation was found between the ADD scale and Non- Acceptance of Emotional Responses and Limited Access to Emotion Regulation Strategies; with Difficulties Engaging in Goal-Directed Behavior, Lack of Emotional Awareness and Lack of Emotional Clarity a weak positive correlation was found.

SA scale showed a weak significant positive correlation with Non-Acceptance of Emotional Responses. DI scale showed no significant correlation with either dimension of emotion regulation difficulties.

\section{Discussion}

The first aim of the present study was to compare the group of maladaptive daydreamers to the group of normal fantasizers regarding their attachment characteristics. The results of the ASQ-H revealed that maladaptive daydreamers had significantly lower scores on the CR scale, indicating that they are less confident in their relationships than non-maladaptive daydreamers. They reported significantly higher scores on the additional four scales that measure certain aspects of attachment anxiety and avoidance. These results suggest that maladaptive daydreamers' attachment is significantly more insecure than the attachment of non-pathological daydreamers.
Table 2 Mean scores and standard deviations of the ASQ-H scales in the group of maladaptive and normal daydreamers

\begin{tabular}{lll}
\hline ASQ-H scales & $\begin{array}{l}\text { Maladaptive daydreamers } \\
\text { M (SD) }\end{array}$ & $\begin{array}{l}\text { Normal daydreamers } \\
\text { M (SD) }\end{array}$ \\
\hline Importance of Relationship for Self (IRS) & $4.04(0.92)$ & $3.29(0.83)$ \\
Confidence in Relations (CR) & $3.21(0.94)$ & $4(0.81)$ \\
Ambivalence, Distance from relationships, & $3.57(0.97)$ & $2.71(0.87)$ \\
$\quad$ Devaluation of self (ADD) & $2.89(0.82)$ & $2.6(0.81)$ \\
Self-advocacy (against relationships) (SA) & $4.77(0.99)$ & $4.47(1.05)$ \\
Dependency, independency (DI) & & \\
\hline
\end{tabular}


Table 3 Median, interquartile range and $p$ value in the study groups for emotion regulation difficulties

\begin{tabular}{|c|c|c|c|}
\hline Subscale & $\begin{array}{l}\text { Maladaptive daydreamers } \\
\text { Mdn } \\
\text { (Q25-Q75) }\end{array}$ & $\begin{array}{l}\text { Normal } \\
\text { daydreamers } \\
\text { Mdn } \\
\text { (Q25-Q75) }\end{array}$ & $\mathrm{p}$ value \\
\hline Non-Acceptance of Emotional Reponses & $\begin{array}{l}2.67 \\
(1.67-3.83)\end{array}$ & $\begin{array}{l}1.83 \\
(1.5-2.5)\end{array}$ & $<0.001$ \\
\hline Difficulties Engaging in Goal-Directed Behavior & $\begin{array}{l}4 \\
(3-4.4)\end{array}$ & $\begin{array}{l}2.6 \\
(2.2-3.4)\end{array}$ & $<0.001$ \\
\hline Impulse Control Difficulties & $\begin{array}{l}2.83 \\
(2.17-3.83)\end{array}$ & $\begin{array}{l}2 \\
(1.67-2.5)\end{array}$ & $<0.001$ \\
\hline Lack of Emotional Awareness & $\begin{array}{l}3.5 \\
(3-4)\end{array}$ & $\begin{array}{l}3.33 \\
(2.83-3.67)\end{array}$ & $=0.0127$ \\
\hline Limited Access to Emotion Regulation Strategies & $\begin{array}{l}3.31 \\
(2.38-4)\end{array}$ & $\begin{array}{l}2.13 \\
(1.63-2.75)\end{array}$ & $<0.001$ \\
\hline Lack of Emotional Clarity & $\begin{array}{l}2.4 \\
(2.2-3)\end{array}$ & $\begin{array}{l}2.2 \\
(1.8-2.6)\end{array}$ & $<0.001$ \\
\hline DERS total score & $\begin{array}{l}3.14 \\
(2.75-3.75)\end{array}$ & $\begin{array}{l}2.39 \\
(2.06-2.83)\end{array}$ & $<0.001$ \\
\hline
\end{tabular}

So, according to the study results, maladaptive daydreamers tend to see themselves as less valuable than others and believe to a lesser extent that other people would love and respect them. They also have difficulties with believing that they can rely on other people when needed.

Based on a more detailed analysis of the scores given on the five scales, specific attachment patterns of problematic daydreamers could be identified. Maladaptive daydreamers seem to struggle with ambivalent feelings regarding their relationships. On the one hand, they feel more insecure in their relationships, expect lower level of love, understanding and caring from important others (CR). They tend to feel that they cannot meet the standards of other people and they are not valuable enough in their relationships; they do not truly understand why other people would like to make contact with them, and they often experience loneliness (IRS and ADD). On the other hand, results revealed that relationships are indeed very important for their self, with special regard to the
Table 4 Correlation table showing Spearman's rho and significance values for the dimensions of attachment and emotion regulation in the group of maladaptive daydreamers $(n=$ 106)

\begin{tabular}{|c|c|c|c|c|c|c|}
\hline $\begin{array}{l}\text { Spearman's rho } \\
\text { coefficient (p } \\
\text { value) }\end{array}$ & $\begin{array}{l}\text { Non- } \\
\text { Acceptance } \\
\text { of } \\
\text { Emotional } \\
\text { Reponses }\end{array}$ & $\begin{array}{l}\text { Difficulties } \\
\text { Engaging in } \\
\text { Goal- } \\
\text { Directed } \\
\text { Behavior }\end{array}$ & $\begin{array}{l}\text { Impulse } \\
\text { Control } \\
\text { Difficulties }\end{array}$ & $\begin{array}{l}\text { Lack of } \\
\text { Emotional } \\
\text { Awareness }\end{array}$ & $\begin{array}{l}\text { Limited } \\
\text { Access to } \\
\text { Emotion } \\
\text { Regulation } \\
\text { Strategies }\end{array}$ & $\begin{array}{l}\text { Lack of } \\
\text { Emotional } \\
\text { Clarity }\end{array}$ \\
\hline $\begin{array}{l}\text { Importance of } \\
\text { Relationship } \\
\text { for Self (IRS) }\end{array}$ & $\begin{array}{l}0.3077 \\
(=0.0013)\end{array}$ & $\begin{array}{l}0.3323 \\
(<0.001)\end{array}$ & $\begin{array}{l}0.3102 \\
(=0.0012)\end{array}$ & $\begin{array}{l}0.0457 \\
(0.6421)\end{array}$ & $\begin{array}{l}0.5359 \\
(<0.001)\end{array}$ & $\begin{array}{l}0.2432 \\
(=0.012)\end{array}$ \\
\hline $\begin{array}{l}\text { Confidence in } \\
\text { Relations (CR) }\end{array}$ & $\begin{array}{l}-0.3698 \\
(<0.001)\end{array}$ & $\begin{array}{l}-0.1844 \\
(=0.0584)\end{array}$ & $\begin{array}{l}-0.1242 \\
(=0.2045)\end{array}$ & $\begin{array}{l}-0.3563 \\
(<0.001)\end{array}$ & $\begin{array}{l}-0.4560 \\
(<0.001)\end{array}$ & $\begin{array}{l}-0.3208 \\
(<0.001)\end{array}$ \\
\hline $\begin{array}{l}\text { Ambivalence } \\
\text { Distance from } \\
\text { relationships, } \\
\text { Devaluation of } \\
\text { self (ADD) }\end{array}$ & $\begin{array}{l}0.5190 \\
(<0.001)\end{array}$ & $\begin{array}{l}0.2236 \\
(<0.05)\end{array}$ & $\begin{array}{l}0.1067 \\
(=0.2763)\end{array}$ & $\begin{array}{l}0.4034 \\
(<0.001)\end{array}$ & $\begin{array}{l}0.4255 \\
(<0.001)\end{array}$ & $\begin{array}{l}0.3478 \\
(<0.001)\end{array}$ \\
\hline $\begin{array}{l}\text { Self-Advocacy } \\
\text { (against } \\
\text { relationships) } \\
\text { (SA) }\end{array}$ & $\begin{array}{l}0.2311 \\
(=0.0171)\end{array}$ & $\begin{array}{l}0.0873 \\
(=0.3736)\end{array}$ & $\begin{array}{l}0.0003 \\
(=0.9973)\end{array}$ & $\begin{array}{l}0.0657 \\
(=0.5031)\end{array}$ & $\begin{array}{l}0.1598 \\
(=0.1017)\end{array}$ & $\begin{array}{l}0.0673 \\
(=0.4928)\end{array}$ \\
\hline $\begin{array}{l}\text { Dependency, } \\
\text { Independency } \\
\text { (DI) }\end{array}$ & $\begin{array}{l}0.0082 \\
(=0.9332)\end{array}$ & $\begin{array}{l}-0.0868 \\
(=0.3761)\end{array}$ & $\begin{array}{l}-0.0070 \\
(=0.9435)\end{array}$ & $\begin{array}{l}-0.0378 \\
(=0.7005)\end{array}$ & $\begin{array}{l}0.0376 \\
(=0.7021)\end{array}$ & $\begin{array}{l}-0.0879 \\
(=0.3704)\end{array}$ \\
\hline
\end{tabular}


presence, opinion and approval by other people (IRS). Due to their ambivalence, while they yearn for the closeness of others, also feel uncomfortable when they get too close to other people or other gets closer to them. Excessive daydreamers are less prone to burden other people with their problems, or if they share their problems with others, they feel ashamed or ridiculous. So, they hold back their negative emotions, without discussing them with anyone, and they might devalue the significance of emotions (ADD). Maladaptive daydreamers consider that requesting support from others is a sign of failure, the preciousness of someone is determined by the accomplishments, and fulfilment of obligations and tasks, as well as effectiveness prevail over relationships (SA). Consequently, they tend to rely on themselves rather than on other people, as dependence causes difficult and uncomfortable feelings to them (DI). So maladaptive daydreamers might show a kind of pseudo-independency that derives not from a stable sense of self, but rather from their ambivalent, contradictory feelings and lower level of confidence in their relationships.

In the case of non-maladaptive daydreamers, a significantly different attachment pattern could be revealed. They have a higher confidence in their relationships, including a more positive sense of self and perception of others' emotional availability, love and support (CR). Relationships are important for them, but at a moderate level, so they are not so preoccupied with them as maladaptive daydreamers are (IRS). Normal daydreamers struggle with less ambivalences regarding relationships, so closeness is not so difficult for them compared to maladaptive daydreamers (ADD). They also show a high level of independency (DI), but they do not think that self-advocacy, effectiveness or a sense of duty are more important than relationships (SA).

These attachment patterns suit specific attachment styles described by Hámori, Dankháziné, Sz, et al. (2016b). In case of maladaptive daydreamers, higher scores on IRS and DI scales, moderate scores on CR and ADD scales and moderate/low scores on SA scale indicate an 'Ambivalentfearful' attachment style. In case of normal daydreamers, higher scores on CR and DI, moderate scores on IRS and lower/moderate scores on ADD and SA suggest a 'Secureindependent' attachment style.

Maladaptive daydreamers' insecure, 'Ambivalent-fearful' attachment style can offer possible explanations for at least some aspects of this maladaptive mental activity. Problematic daydreamers' contradictory, ambivalent feelings make them difficult to form and maintain significant interpersonal relationships. As they want to avoid confrontation with anticipated unpleasant interpersonal experiences, they tend to invest less energy in their real relationships, and/or their existing relationships seem to be superficial. This way they often become isolated and lonely, so as a possible compensation, they might create the desired relationships in their fantasy, that they experience much safer and much controllable. This conclusion seems to be in line with the literature of maladaptive daydreaming (Bigelsen et al., 2016;Somer, 2002 ; Somer, Somer, \& Jopp, 2016a ; b). Initial research in the field of maladaptive daydreaming revealed that maladaptive daydreamers' fantasy world often replaces real life interactions and interpersonal experiences, causing severe functional impairment (Somer, 2002). Somer (2002) in a small clinical sample $(n=6)$ described the phenomenon of maladaptive daydreaming, in which study participants suffered from aversive childhood experiences, lived a lonely life, and even in adulthood the majority of them lived alone without friends and romantic relationships. According to further studies (Somer, 2002; Somer, Somer, \& Jopp, 2016a; b), an important function of excessive fantasy activity is the creation of loving, shooting, supporting and safe life with the imagination of responsive and sensitive parents, trustful friends and romantic relationships. As maladaptive daydreamers often experienced rejection, neglect and loneliness (Somer, 2002; Somer, Somer, \& Jopp, 2016a; b) in their childhood and later, fantasized ideal relationships tend to compensate these interpersonal deficiencies and their yearning for actual relationships. The compensatory inner world seems to be so rewarding that daydreamers would rather choose the fantasy world instead of the reality. Because of the private nature of this fantasy activity, and because of the accompanied physical movements (such as pacing, rocking, running), facial expressions and vocalization, maladaptive daydreamers engage in fantasizing when other people are not present. Thus, real life interactions are incompatible with this activity and solitude of the daydreamers seems to be a necessary condition for maladaptive daydreaming (Bigelsen \& Schupak, 2011; b), further distancing the individual from real life scenarios and connections.

The second aim of the study was to compare the emotion regulation difficulties of maladaptive to normal daydreamers. The results revealed that problematic daydreamers showed a significantly higher level of emotion regulation deficits compared to normal fantasizers. Problematic daydreamers react with intense negative emotions (such as anger, embarrassment, guilt) when they experience negative emotions (NonAcceptance of Emotional Reponses). When they feel upset, they experience difficulty with getting work done, focusing or concentrating (Difficulties Engaging in Goal-Directed Behavior). They experience their emotions as less controllable, and when they feel upset, they often lose control over their behaviour (Impulse Control Difficulties). Maladaptive daydreamers are less attentive to their feelings, and when they feel upset, they believe less that their feelings are important or valid, they do not take time to understand their feelings (Lack of Emotional Awareness). They consider negative emotions permanent, believe that they are less effective in coping with them, and rather wallow in their negative feelings (Limited Access to Emotion Regulation Strategies). 
Maladaptive daydreamers are less clear about their feelings, they often feel confused about and experience difficulty with making sense out of their feelings (Lack of Emotional Clarity).

In sum, the results on the DERS scale revealed that maladaptive daydreamers are less attentive to their feelings and consider their feelings less important. They are less able to effectively identify their feelings, cannot accept the negative emotions and are afraid of experiencing them. They often experience secondary negative feelings, such as embarrassment, guilt or irritation. Problematic daydreamers are not able to cope adequately with these emotions as they have limited access to emotion regulation strategies; so, when they have negative emotions, they experience difficulty concentrating and productivity becomes impaired. As a consequence of unsuccessful emotion regulation intensions, problematic daydreamers often experience themselves as overwhelmed, helpless or incompetent. As they do not have adaptive emotion regulation strategies, they might release these difficult negative feelings in their fantasy world.

Previous studies identified an important coping function of maladaptive daydreaming; excessive fantasy activity might be developed as an emotion regulation strategy to achieve selfsooth and calm, in response to aversive childhood experiences, loneliness, bullying from peers and negligence, as well as to cope with daily frustrations and distress (Bigelsen \& Schupak, 2011; Pietkiewicz et al., 2018; Somer, 2002; Somer, Somer, \& Jopp, 2016a). Maladaptive daydreaming often functions as a protective bubble or a distraction from stressors, obligations and worries (Somer et al., 2019). Thus, based on previous findings, maladaptive daydreaming might be a strategy to cope with negative emotions, as well as a way to experience positive emotions (such as calmness, happiness, relief) (West \& Somer, 2020). However, further studies revealed that poorer ability of regulating emotions was related to a higher degree of the symptoms of maladaptive daydreaming, as well as neither maladaptive, nor immersive daydreaming seemed to be adaptive emotion regulation strategy. The results suggest that excessive daydreaming activity might only provide temporary relief from negative emotions, but it cannot be considered as a healthy and mature coping mechanism (Greene et al., 2020; West \& Somer, 2020). The findings of the present study confirmed previous studies' results (Greene et al., 2020; West \& Somer, 2020), in which maladaptive daydreamers showed deficits regarding every aspects of emotion regulation. The present study also revealed that maladaptive daydreamers experienced a higher level of emotion regulation difficulties than normal daydreamers. Vivid fantasizing might provide an opportunity to find a way of emotion regulation as the individual determines and controls the flow of imagination, the storylines, and the destiny of the characters in the fantasy world (Somer et al., 2019).
The third aim of the study was to reveal specific connections between the dimensions of attachment and emotion regulation difficulties in the group of problematic daydreamers. IRS scale showed a moderate significant positive correlation with Limited Access to Emotion Regulation Strategies, suggesting that emotional importance of relationships for the self and overestimation of the presence and opinion of others, can be associated with the restricted capacity of handling negative, distressful emotions. A weak correlation between the IRS scale and Non-Acceptance of Emotional Responses, Difficulties Engaging in Goal- Directed Behavior, Impulse Control Difficulties and Lack of Emotional Clarity, means that the overestimation of relationships for the self is weakly associated with secondary negative feelings, difficulties in focusing and getting work done and out of control behaviours in cases of distress, as well as with confusion of recognizing emotions. CR scale showed a moderate significant negative correlation with Limited Access to Emotion Regulation Strategies, which suggests that the confidence in relations has an inverse association with the belief that little can be done in case of negative emotions. Weak negative correlations with Non-Acceptance of Emotional Responses, Lack of Emotional Awareness and Lack of Emotional Clarity suggest an inverse relationship between the degree of security experienced in close relationships and the degree of experiencing secondary negative feelings in case of distress, the limited awareness of emotional signals and insecure identification of emotions. A moderate significant positive correlation was found between ADD scale and Non- Acceptance of Emotional Responses and Limited Access to Emotion Regulation Strategies, which suggest that mixed, ambivalent feelings and discomfort in relationships, and the devaluation of the self, are related to the presence of shame, guilt and weakness when feeling distressed, and to the limited availability of emotion regulation techniques to cope with negative emotions. ADD scale showed a weak correlation with Difficulties Engaging in Goal-Directed Behavior, Lack of Emotional Awareness and Lack of Emotional Clarity, suggesting that ambivalent feelings in close relationships and depreciation of the self are weakly related to the problems of focusing and concentrating when the individual feel upset, and to the limited awareness of emotional signals and insecure identification of emotions. SA scale showed only a weak correlation with Non-Acceptance of Emotional Responses, which result reveals that self-advocacy, sense of duty and the priority of productivity are weakly related to the presence of secondary negative feelings (shame, anger) when the individual has negative emotions.

These results confirmed the importance of examining the connections between attachment and emotion regulation. As for the strong and moderate correlations, it seems that in maladaptive daydreamers' group, the overestimation of relationships regarding self-evaluation, self-confidence, the intense worry about relationships, and the experience of loneliness 
are associated with the restricted capacity for handling negative, distressful emotions. The inverse connection between confidence in relationships and limited access to strategies when regulating emotions, suggests that security in close relationships might be related to the belief that the individual in case of distress is able to cope with negative emotions, while relationship ambivalence and discomfort, intimacy avoidance and self-devaluation are related to the belief that the individual cannot regulate his/her negative emotions, and reacts with non-accepting reactions to distress.

Although we measured only correlations between the dimensions of attachment and emotion regulation difficulties, it seems that specific segments of attachment are related to emotion regulation deficits. In the case of problematic daydreamers, the overestimation of relationships for self-determination, self-evaluation and the presence of significant others and approval by them, preoccupation and anxiety about the sufficient/insufficient closeness of others (IRS scale) are correlated with the restricted capacity to regulate emotions in case of distress. Furthermore, the security and confidence experienced in close relationships moderately connected to the belief that negative mental states will not last a long time when experiencing negative emotions. However, ambivalent feelings, discomfort in relationships and efforts to distance intimate relationships are related to non-acceptance of emotional responses and limited access to emotion regulation strategies.

The constant availability of the attachment figure and the sense of security have significant effects on affect regulation and on interpersonal behavior. Security in close relationships facilitates the development of resources for the maintenance of tranquility in case of distress and extends the capacities of the individual. During positive interactions with the attachment figure, the individual learns that the experience of distress and negative emotions can be managed, and it is possible to deal with threats (Mikulincer \& Shaver, 2003). Attachment security is related to more optimism about life, openness to emotions, less catastrophic forecast of threats, more accuracy in experiencing and expressing emotions, more confidence regarding the ability to cope with threats and more adaptive emotion regulation strategies (Mikulincer \& Shaver, 2019). Secure individuals have a positive attitude regarding the challenges of life which results in the constructive and adaptive way of coping (e.g. active problem-solving strategies, seeking of proximity when the individual is distressed and positive and meaningful transformation of problems) (Mikulincer \& Shaver, 2003). However, attachment anxiety and attachmentrelated avoidance - which might have been adaptive during childhood to survive the inconsistent behavior of the attachment figure, but became maladaptive in later relationships-, can be related to the abnormal representation of the self and the world, to the repeated presence of negative emotions, and to emotion regulation difficulties. Consequently, insecure attachment strategies might lead to poor mental and physical health (Mikulincer \& Shaver, 2019). Avoidant individuals tend to separate their emotions from thoughts and behaviors, have a "facade of security" and often the experience of distress remains unresolved leading to the impairment of coping (Mikulincer \& Shaver, 2012). Avoidant attachment is related to cognitive distancing and emotional disengagement in response to distress and threat, while attachment anxiety is associated with mental rumination about threatening events and increasing attention to those stimuli which activate distress (Mikulincer \& Shaver, 2019). Individuals who experience attachment anxiety are often characterized by the amplification of emotions, overabundance of worries and negative, depressive reactions to potential/ real losses (Mikulincer \& Shaver, 2012).

\section{Strengths and Limitations}

The strength of the study is the relatively large sample size. 717 individuals were recruited, from which 106 maladaptive daydreamers were screened. Access of the population of maladaptive daydreamers is highly problematic, as these individuals feel intense shame and guilt about their excessive behaviour and tend to hide their activity even from parents, friends and professionals such as psychologists or psychiatrists (Bigelsen et al., 2016; Somer, Somer, \& Jopp, 2016a). Online recruitment procedure, however, seems to be appropriate to call maladaptive daydreamers for participation and to broaden the knowledge about the phenomenon (e.g., AbuRayya, Somer, \& Meari-Amir, 2019; Bigelsen et al., 2016; Bigelsen \& Schupak, 2011; Greene et al., 2020; Somer, Lehrfeld, et al., 2016).

One limitation of the study is the composition of the sample as participants were recruited in different ways: from online communities and groups, and from the University of Debrecen. However, the aim of the study was to screen maladaptive daydreamers from the samples and to examine the attachment characteristics and difficulties in emotion regulation among maladaptive and normal fantasizers. Another limitation is that the questionnaire package was filled by the individuals online, thus a specific segment of the population could participate in the study, those who had the necessary Information Technology skills. Consequently, in the sample those who had primary education, or who were unemployed or retired at the time of the research, were underrepresented. As for the gender proportion, women were overrepresented, and regarding employment status students formed the majority of the sample, which might be caused by the large sample size of the student sample. These factors might influence the generalizability of the results. 


\section{Conclusions}

Previous studies intended to explore among others the phenomenology of maladaptive daydreaming (e.g. Bigelsen et al., 2016; Bigelsen \& Schupak, 2011; Somer, 2002; Somer et al., 2019; Somer, Somer, \& Jopp, 2016b), created appropriate measure to screen and diagnose the phenomenon (Somer, Lehrfeld, et al., 2016; Somer, Soffer-Dudek, Ross, \& Halpern, 2017b), revealed the comorbid psychopathologies (Somer, Soffer-Dudek, \& Ross, 2017a) and explored the antecedents, maintaining and mediating factors of maladaptive daydreaming (e.g. Ferrante, Marino, Guglielmucci, \& Schimmenti, 2020; Somer \& Herscu, 2017; Somer, Somer, \& Jopp, 2016a). As researchers explored that maladaptive daydreaming was developed in early childhood (Somer, Somer, \& Jopp, 2016a), it seemed to be important to study some etiological segments of maladaptive daydreaming for the better understanding of the early period of personality development. The focus of our research - examining the attachment characteristics and emotion regulation problems among problematic daydreamers- derived from the contents of maladaptive daydreaming, severe functional impairment and social isolation of maladaptive daydreamers described in previous studies (Bigelsen \& Schupak, 2011; Somer, 2002; Somer, Somer, \& Jopp, 2016a; b). Our intention was to gain better account for the pathogenesis of the phenomenon and to give some new contributions to its treatment approaches. To the best of our knowledge, this research was the first attempt to explore the attachment characteristics among maladaptive daydreamers.

Based on the results of the study, a specific attachment style, i.e. 'Ambivalent- fearful', was identified among problematic daydreamers. According to this finding, although maladaptive daydreamers feel intense desire for relationships, and close relations are important for their self, they do not experience sufficient confidence and security in the relationships, and even have ambivalent, unpleasant feelings in them. Thus, due to their ambivalence and relational fears, they might avoid real-life relationships and show a kind of pseudo-independency. Although the fantasy world might provide temporarily positive feelings and pleasant experiences, problematic daydreaming deprives the individual from the corrective effect of real interpersonal experiences. Moreover, social isolation and loneliness can reinforce the negative representations of the self and others and consequently attachment insecurity.

The results of emotion regulation difficulties highlight that for problematic daydreamers negative emotions might be overwhelming, as on the one hand they are less aware of their feelings and experience difficulties with identifying these emotions, while on the other hand they are less able to cope with their negative emotions and to control their impulses. Thus, negative feelings have a negative impact on their goaldirected behaviours, and maladaptive daydreamers, having limited access to emotion regulation strategies, consider the difficult situations and feelings as permanent.

A main conclusion of the study is that in the background of problematic daydreaming there might be significant attachment injuries and severe emotion regulation deficits. For effective psychotherapeutic treatment of maladaptive daydreamers, exploration of early childhood (attachment) experiences, focus on adult attachment style, as well as identification and modification of missing or maladaptive emotion regulation strategies are indispensable. Stable, secure and supporting therapeutic relationship might facilitate the correction of problematic daydreamers' attachment patterns, including representation of the self, the other and the relationship. Parallel with attachment-focus, the present study confirmed an earlier presumption according to which an important segment of the intervention with maladaptive daydreamers might be the development and acquisition of adaptive emotion regulation strategies (West \& Somer, 2020), however, a secure, soothing, and emotionally validating atmosphere might support itself the tolerance and alleviation of distress and negative feelings (Greenberg, 2007).

In addition to understand the pathogenesis of maladaptive daydreaming, the results revealed by the present study might facilitate the comprehension of the maintaining factors of the phenomenon as well, giving contributions to the development of psychotherapeutical treatment of maladaptive daydreaming.

One limitation of the study was the sample composition, as university students comprised significant proportion of the sample $(66.1 \%)$, thus generalizability of the results is limited. As the majority of the sample was formed by students, it might be important to discuss the potential difficulties experienced by university students suffering from problematic daydreaming. While resilient students can easily focus on learning and can be successful both academically and in terms of interpersonal relationships (Gamble \& Crouse, 2020), maladaptive daydreaming is characterized by intense shame, distress, loneliness and academic and interpersonal impairment (Somer, 2002). Successful transition from secondary school to college or university is a challenge, and balancing between studies, work and relationships might be distressful even for resilient students. When planning for interventions on the level of postsecondary institutions to support those who experience anxiety, severe distress, unrealistic expectations regarding academic performance or other types of mental health issues (i.e. problematic daydreaming), several strategies can be offered (such as description about learning how to reduce anxiety; art therapy to increase well-being; mindfulness training; communication workshop). Art therapy, communication practice, mindfulness training and anxiety reduction techniques might be useful in case of maladaptive daydreamers as well, who often experience anxiety, have a difficulty to create and maintain relationships, and to anchor in the present moment instead of fantasizing (Somer, 2002; Somer, 2018; Somer, Soffer-Dudek, 
\& Ross, 2017a). Another intervention strategy for problematic daydreamers might be the dissemination of information about the existence of university/ college resources and how these resources can be available for those who need help (for example counseling, health promotion or mental health services, online support groups) (Gamble \& Crouse, 2020).

Another limitation of the study was the online recruitment method, which could target those individuals, who have the necessary technical equipment and knowledge to fulfil the questionnaire package. It should be also highlighted that data generalizability is influenced by the overrepresentation of women, students and those participants who have secondary or tertiary education.

In this sample more than a half of the maladaptive daydreamers' group (55.66\%) reported to have single relationship status, while $38.68 \%$ were in relationship or married. Previous studies suggested that maladaptive daydreamers often have academic and occupational problems, they often experience loneliness, and some of them never had any romantic or close relationship. They experience intense shame and guilt about their excessive mental activity and tend to hide their daydreaming activity even from their parents and close relatives (Bigelsen \& Schupak, 2011; Somer, 2002; Somer, Somer, \& Jopp, 2016a; b). Functional impairment and severe distress experienced by maladaptive daydreamers, as well as their secretive behavior might influence functionality of close relatives. However, the effect of problematic daydreaming on maladaptive daydreamers' relatives (parents, romantic partners, close friends) has not been investigated yet. As relatives of those who suffer from chronic mental disease may experience physical, social, mental and economic difficulties (Yazici et al., 2016), it seems to be useful to investigate the effects of maladaptive daydreaming on close relatives.

Hopefully, this study may contribute to the scant literature of maladaptive daydreaming and will stimulate further research regarding the early experiences of maladaptive daydreamers and their consequential effects on later relationships, subjective well-being and emotion regulation. However, future research involving case studies and controlled clinical research, as well as the psychotherapeutical practice itself should shed light on the applicability of the results generated by the present study, regarding the injuries of attachment and emotion regulation experienced by maladaptive daydreamers, and should reveal more therapeutic intervention targets of the population of problematic daydreamers.

Funding Open access funding provided by University of Debrecen. This research was supported in part by EFOP-3.6.3-VEKOP-16-2017-00009 co-financed by EU and the European Social Found.

Data Availability The datasets generated during and/or analysed during the current study are available from the corresponding author on reasonable request.

\section{Declarations}

Conflict of Interest The authors declare that there is no conflict of interest.

Open Access This article is licensed under a Creative Commons Attribution 4.0 International License, which permits use, sharing, adaptation, distribution and reproduction in any medium or format, as long as you give appropriate credit to the original author(s) and the source, provide a link to the Creative Commons licence, and indicate if changes were made. The images or other third party material in this article are included in the article's Creative Commons licence, unless indicated otherwise in a credit line to the material. If material is not included in the article's Creative Commons licence and your intended use is not permitted by statutory regulation or exceeds the permitted use, you will need to obtain permission directly from the copyright holder. To view a copy of this licence, visit http://creativecommons.org/licenses/by/4.0/.

\section{References}

Abu-Rayya, H. M., Somer, E., \& Meari-Amir, S. (2019). The psychometric properties of the Arabic 16-item maladaptive daydreaming scale (MDS-16-AR) in a multicountry Arab sample. Psychology of Consciousness: Theory, Research, and Practice, 6(2), 171-183. https://doi.org/10.1037/cns0000183.

Ainsworth, M. D. (1985). Patterns of infant-mother attachments: Antecedents and effects on development. Bulletin of the New York Academy of Medicine, 61(9), 771-791.

An, L., Liu, C., Zhang, N., Chen, Z., Ren, D., Yuan, F., Yuan, R., Bi, Y., Ji, L., Guo, Z., Ma, G., Xu, F., Yang, F., Zhu, L., Robert, G., Xu, Y., He, L., Bai, B., Yu, T., \& He, G. (2019). GRIK 3 rs 490647 is a common genetic variant between personality and subjective wellbeing in Chinese Han population. Emerging Science Journal, 3(2), 78. https://doi.org/10.28991/esj-2019-01171.

Bariola, E., Gullone, E., \& Hughes, E. K. (2011). Child and adolescent emotion regulation: The role of parental emotion regulation and expression. Clinical Child and Family Psychology Review, 14(2), 198-212. https://doi.org/10.1007/s10567-011-0092-5.

Berking, M., \& Wupperman, P. (2012). Emotion regulation and mental health: Recent findings, current challenges, and future directions. Current Opinion in Psychiatry, 25(2), 128-134. https://doi.org/10. 1097/YCO.0b013e3283503669.

Bigelsen, J., \& Schupak, C. (2011). Compulsive fantasy: Proposed evidence of an under-reported syndrome through a systematic study of 90 self-identified non-normative fantasizers. Consciousness and Cognition, 20, 1634-1648. https://doi.org/10.1016/j.concog.2011. 08.013.

Bigelsen, J., Lehrfeld, J. M., Jopp, D. S., \& Somer, E. (2016). Maladaptive daydreaming: Evidence for an under-researched mental health disorder. Consciousness and Cognition, 42, 254-266. https://doi.org/10.1016/j.concog.2016.03.017.

Bowlby, J. (1973). Attachment and loss: Volume II: Separation, anxiety and anger. In Attachment and loss: Volume II: Separation, anxiety and anger (pp. 1-429). London: The Hogarth press and the institute of psycho-analysis.

Bowlby, J. (1982). Attachment and loss: Retrospect and prospect. American Journal of Orthopsychiatry, 52(4), 664-678.

Bowlby, J. (1988). A secure base: Parent-child attachment and healthy human development. New York, NY: Basic Books.

Cassidy, J. (1994). Emotion regulation: Influences of attachment relationships. Monographs of the Society for Research in Child Development, 59(2-3), 228-283. https://doi.org/10.2307/1166148. 
Cooper, M. L., Shaver, P. R., \& Collins, N. L. (1998). Attachment styles, emotion regulation, and adjustment in adolescence. Journal of Personality and Social Psychology, 74(5), 1380-1397. https://doi. org/10.1037/0022-3514.74.5.1380.

Cummings, E, M., \& Cummings, J, S. (2002). Parenting and attachment. In M. H. Bornstein (Ed.), Handbook of parenting. Volume 5: Practical Issues in Parenting (2nd Ed.) (pp. 35-58). Mahwah, NJ: Lawrence Erlbaum Associates Publishers.

Feeney, J, A., Noller, P., \& Hanrahan, M. (1994). Assessing adult attachment. In M. B. Sperling \& W. H. Berman (Eds.), Attachment in adults: Clinical and developmental perspectives (pp. 128-152). New York, NY: Guilford Press.

Ferrante, E., Marino, A., Guglielmucci, F., \& Schimmenti, A. (2020). The mediating role of dissociation and shame in the relationship between emotional trauma and maladaptive daydreaming. Psychology of Consciousness: Theory, Research, and Practice. Advance online publication. doi:https://doi.org/10.1037/cns0000253

Gamble, B. J., \& Crouse, D. (2020). Strategies for supporting and building student resilience in Canadian secondary and post-secondary educational institutions. Science Medicine Journal, 2(2), 70-76. https://doi.org/10.28991/SciMedJ-2020-0202-4.

Gratz, K. L., \& Roemer, L. (2004). Multidimensional assessment of emotion regulation and dysregulation: Development, factor structure, and initial validation of the difficulties in emotion regulation scale. Journal of Psychopathology and Behavioral Assessment, 26(1), 4154. https://doi.org/10.1023/B:JOBA.0000007455.08539.94.

Greenberg, L. S. (2007). Emotion coming of age. Clinical Psychology: Science and Practice, 14(4), 414-421. https://doi.org/10.1111/j. 1468-2850.2007.00101.x.

Greene, T., West, M., \& Somer, E. (2020). Maladaptive daydreaming and emotional regulation difficulties: A network analysis. Psychiatric Research, 285, 112799. Advance online publication. https://doi. org/10.1016/j.psychres.2020.112799.

Gross, J. J., \& Muñoz, R. F. (1995). Emotion regulation and mental health. Clinical Psychology: Science and Practice, 2(2), 151-164. https://doi.org/10.1111/j.1468-.

Gy, K. (2008). Érzelemszabályozás krónikus fájdalomban. Eötvös Loránd Tudományegyetem: Doktori disszertáció.

Hámori, E., Dankháziné, H. E., Horváth-Szabó, K., Martos, T., Kézdy, A., \& Sz, U. (2016a). A felnőtt kötődés mérése: a kötődési stílus kérdőív (ASQ-H) magyar változata. Alkalmazott Pszichológia, 16(3), 119-144.

Hámori, E., Dankháziné, H. E., Sz, U., Martos, T., Kézdy, A., \& HorváthSzabó, K. (2016b). A felnőtt kötődés új típusai? Eredmények a Kötődési Stílus Kérdőív (ASQ-H) magyar változatával. Alkalmazott Pszichológia, 16(3), 57-77.

Killingsworth, M. A., \& Gilbert, D. T. (2010). A wandering mind is an unhappy mind. Science, 330(6006), 932-932.

Kochanska, G. (2001). Emotional development in children with different attachment histories: The first three years. Child Development, 72(2), 474-490. https://doi.org/10.1111/1467-8624.00291.

Macfie, J., \& Swan, S. (2009). Representations of the caregiver-child relationship and of the self, and emotion regulation in the narratives of young children whose mothers have borderline personality disorder. Development and Psychopathology, 21(3), 993-1011. https:// doi.org/10.1017/S0954579409000534.

McMillan, R. L., Kaufman, S. B., \& Singer, J. L. (2013). Ode to positive constructive daydreaming. Frontiers in Psychology, 4, 626. https:// doi.org/10.3389/fpsyg.2013.00626.

Mikulincer, M., \& Shaver, P. R. (2003). The attachment behavioral system in adulthood: Activation, psychodynamics, and interpersonal processes. In M. P. Zanna (Ed.), Advances in experimental social psychology, Vol. 35 (p. 53-152). Elsevier Academic Press. https:// doi.org/10.1016/S0065-2601(03)01002-5.
Mikulincer, M., \& Shaver, P. R. (2012). An attachment perspective on psychopathology. World Psychiatry, 11(1), 11-15. https://doi.org/ 10.1016/j.wpsyc.2012.01.003.

Mikulincer, M., \& Shaver, P. R. (2019). Attachment orientations and emotion regulation. Current Opinion in Psychology, 25, 6-10. https://doi.org/10.1016/j.copsyc.2018.02.006.

Mooneyham, B. W., \& Schooler, J. W. (2013). The costs and benefits of mind-wandering: A review. Canadian Journal of Experimental Psychology/Revue canadienne de psychologie expérimentale, 67(1), 11-18. https://doi.org/10.1037/a0031569.

Morris, A. S., Silk, J. S., Steinberg, L., Myers, S. S., \& Robinson, L. R. (2007). The role of the family context in the development of emotion regulation. Social Development, 16(2), 361-388. https://doi.org/10. 1111/j.1467-9507.2007.00389.x.

Mortazavizadeh, Z., \& Forstmeier, S. (2018). The role of emotion regulation in the association of adult attachment and mental health: A systematic review. Archives of Psychology, 2(9). doi: https://doi.org/ 10.31296/aop.v2i9.83

Palitsky, D., Mota, N., Afifi, T. O., Downs, A. C., \& Sareen, J. (2013). The association between adult attachment style, mental disorders, and Suicidality. The Journal of Nervous and Mental Disease, 201(7), 579-586. https://doi.org/10.1097/nmd.0b013e31829829ab.

Pascuzzo, K., Moss, E., \& Cyr, C. (2015). Attachment and emotion regulation strategies in predicting adult psychopathology. SAGE Open, 5(3), 1-15. https://doi.org/10.1177/2158244015604695.

Pietkiewicz, I. J., Nęcki, S., Bańbura, A., \& Tomalski, R. (2018). Maladaptive daydreaming as a new form of behavioral addiction. Journal of Behavioral Addictions, 7(3), 838-843. https://doi.org/10. 1556/2006.7.2018.95

Poerio, G. L., Totterdell, P., Emerson, L. M., \& Miles, E. (2015). Love is the triumph of the imagination: Daydreams about significant others are associated with increased happiness, love and connection. Consciousness and Cognition, 33, 135-144. https://doi.org/10. 1016/j.concog.2014.12.011.

Prion, S. K., \& Haerling, K. (2014). Making sense of methods and measurement: Spearman-rho ranked-order correlation coefficient. Clinical Simulation in Nursing, 10, 535-536. https://doi.org/10. 1016/j.ecns.2014.07.005.

Regis, M. (2013). Daydreams and the function of fantasy. London: Palgrave Macmillan.

Sándor, A., Münnich, Á., \& Molnár, J. (2020). Psychometric properties of the maladaptive daydreaming scale in a sample of Hungarian daydreaming- prone individuals. Journal of Behavioral Addictions, 9(3), 853-862. https://doi.org/10.1556/2006.2020. 00050.

Schimmenti, A., Sideli, L., La Marca, L., Gori, A., \& Terrone, G. (2019). Reliability, validity, and factor structure of the maladaptive daydreaming scale (MDS-16) in an Italian sample. Journal of Personality Assessment, 102(5), 689-701. https://doi.org/10.1080/ 00223891.2019 .1594240 .

Singer, J. L. (1975). Navigating the stream of consciousness: Research in daydreaming and related inner experience. American Psychologist, 30(7), 727-738. https://doi.org/10.1037/h0076928.

Soffer-Dudek, N., \& Somer, E. (2018). Trapped in a daydream: Daily elevations in maladaptive daydreaming are associated with daily psychopathological symptoms. Frontiers in Psychiatry, 9(194), 114. https://doi.org/10.3389/fpsyt.2018.00194.

Somer, E. (2002). Maladaptive daydreaming: A qualitative inquiry. Journal of Contemporary Psychotherapy, 32(2), 197-212.

Somer, E. (2018). Maladaptive daydreaming: Ontological analysis, treatment rationale; a pilot case report. Frontiers in the Psychotherapy of Trauma and Dissociation, 1(2), 1-22.

Somer, E., \& Herscu, O. (2017). Childhood trauma, social anxiety, absorption and fantasy dependence: Two potential mediated pathways to maladaptive daydreaming. Journal of Addictive Behaviors, 
Therapy \& Rehabilitation, 6(3), 1-5. https://doi.org/10.4172/23249005.1000170

Somer, E., Lehrfeld, J., Bigelsen, J., \& Jopp, D. S. (2016). Development and validation of the maladaptive daydreaming scale (MDS). Consciousness and Cognition, 39, 77-91. https://doi.org/10.1016/ j.concog.2015.12.001.

Somer, E., Somer, L., \& Jopp, D. S. (2016a). Childhood antecedents and maintaining factors in maladaptive daydreaming. The Journal of Nervous and Mental Disease, 204(06), 474-478. https://doi.org/ 10.1097/NMD.0000000000000507.

Somer, E., Somer, L., \& Jopp, D. S. (2016b). Parallel lives: A phenomenological study of the lived experience of maladaptive daydreaming. Journal of Trauma \& Dissociation, 17(5), 561-576. https://doi.org/10.1080/15299732.2016.1160463.

Somer, E., Soffer-Dudek, N., \& Ross, C. A. (2017a). The comorbidity of daydreaming disorder (maladaptive daydreaming). The Journal of Nervous and Mental Disease, 205(7), 525-530.

Somer, E., Soffer-Dudek, N., Ross, C. A., \& Halpern, N. (2017b). Maladaptive daydreaming: Proposed diagnostic criteria and their assessment with a structured clinical interview. Psychology of Consciousness: Theory, Research, and Practice, 4(2), 176-189. https://doi.org/10.1037/cns0000114.

Somer, E., Somer, L., \& Halpern, N. (2019). Representations of maladaptive daydreaming and the self: A qualitative analysis of drawings. The Arts in Psychotherapy, 63, 102-110. https://doi.org/10.1016/j. aip.2018.12.004.

Szentmiklósi, J. A. (2011). Az orvostudományi kutatások etikai engedélyezése: elméleti és gyakrolati szempontok. In Z. Bereczki
\& L. Muszbek (Eds.), A klinikai kutatások tervezése és kivitelezése: elméleti és módszertani alapok (pp. 179-193). Budapest: Medicina Könyvkiadó Zrt.

Thompson, R. A. (1994). Emotion regulation: A theme in search of definition. Monographs of the Society for Research in Child Development, 59(2/3), 25-52. https://doi.org/10.2307/1166137.

Thompson, R, A. (2008). Early attachment and later development: Familiar questions, new answers. In J. Cassidy \& P. R. Shaver (Eds.), Handbook of attachment: Theory, research, and clinical applications (p. 348-365). New York, NY: Guilford Press.

Waters, S. F., Virmani, E. A., Thompson, R. A., Meyer, S., Raikes, H. A., \& Jochem, R. (2010). Emotion regulation and attachment: Unpacking two constructs and their association. Journal of Psychopathology and Behavioral Assessment, 32(1), 37-47. https://doi.org/10.1007/s10862-009-9163-z.

West, M., \& Somer, E. (2020). Empathy, emotion regulation, and creativity in immersive daydreaming. Imagination, Cognition and Personality: Consciousness in Theory, Research, and Clinical Practice, 39(4), 358-373. https://doi.org/10.1177/ 0276236619864277.

Yazici, E., Karabulut, Ü., Yildiz, M., Baskan Tekeş, S., Inan, E., Çakir, U., Boşgelmez, Ş., \& Turgut, C. (2016). Burden on caregivers of patients with schizophrenia and related factors. Noro Psikiyatri Arsivi, 53(2), 96-101. https://doi.org/10.5152/npa.2015.9963.

Publisher's Note Springer Nature remains neutral with regard to jurisdictional claims in published maps and institutional affiliations. 